\title{
Transport of $\alpha$-Aminoisobutyrate into Trypanosoma brucei brucei
}

\author{
By K. P. COOLBEAR AND M. MIDGLEY* \\ Department of Biochemistry, University of Hull, Hull HU6 7RX, UK
}

(Received 30 November 1983; revised 30 March 1984)

\begin{abstract}
The uptake of $\alpha$-aminoisobutyrate (AIB) by washed cell suspensions of bloodstream forms of Trypanosoma brucei brucei has been shown to be an energy-dependent process. No metabolism of AIB was detected under conditions leading to a 100-fold accumulation of AIB within the organism. Kinetic studies revealed that AIB uptake involved two components; that operating at low substrate concentrations had an apparent $K_{\mathrm{m}}$ of $4.6 \mathrm{mM}$. Experiments with ionophores such as gramicidin and carbonylcyanide $m$-chlorophenylhydrazone were consistent with the AIB uptake system operating as a $\mathrm{H}^{+}$-symporter responding to the electrochemical gradient of $\mathrm{H}^{+}$, the major component of which was the membrane potential.
\end{abstract}

\section{INTRODUCTION}

The mechanisms of energy-coupling to active transport mechanisms in bloodstream forms of trypanosomes are currently unknown. Amino acid transport has been studied in some detail by Voorheis $(1971,1977,1980)$, who has shown that at least four distinct systems operate for these compounds. It was proposed, following studies on threonine uptake, that a proton electrochemical gradient $\left(\Delta \bar{\mu}_{\mathrm{H}}\right)$ or an alkali-metal cation gradient did not play a significant role in amino acid accumulation but that a glycolytic intermediate played a key role (Voorheis, 1980).

Previous experiments, concerned with the transport of the non-metabolizable amino acid $\alpha$-aminoisobutyrate (AIB) into the trypanosomatid Crithidia fasciculata, have produced results consistent with the operation of a proton-symport system for the active transport of this compound (Midgley, 1978). Further evidence for this was the demonstration of a significant, metabolically-generated membrane potential $(\Delta \psi)$ in this organism (Stephenson \& Midgley, 1980). Such a potential often constitutes the major component of an ion electrochemical gradient, e.g. $\Delta \bar{\mu}_{H^{*}}$ or $\Delta \bar{\mu}_{\mathrm{N}_{2}}$ (Eddy, 1978; Hamilton, 1975).

Recent work has provided evidence for the existence of an appreciable $\Delta \psi(-130 \mathrm{mV})$ across the cytoplasmic membrane of Trypanosoma brucei brucei (Midgley, 1983a,b). The maintenance of this $\Delta \psi$ was sensitive to ionophores such as gramicidin and tetrachlorosalicylanilide (TCS), suggesting that it arose as a result of electrogenic $\mathrm{H}^{+}$extrusion (Midgley, 1983a). Thus bloodstream forms of $T$. b. brucei probably maintain an appreciable $\Delta \bar{\mu}_{\mathrm{H}}$, and this has prompted an examination of the role of this gradient in energy-coupling for AIB transport in this organism. Initial experiments were concerned with the general characteristics of AIB transport in order to justify its use in studies of energy-coupling.

\section{METHODS}

Growth and harvesting of the organism. The organism used was Trypanosoma brucei brucei $8 / 18$ maintained, grown for experimental work in laboratory rats and harvested as previously described (Midgley, 1983a). Buffer solutions based on 4-(2-hydroxyethyl)-1-piperazine propane sulphate (HEPPS) were used for the resuspension of the organism for transport assays and related studies. The composition of the medium designated $\mathrm{Na} / \mathrm{HEPPS} / \mathrm{glucose}$

\footnotetext{
Abbreviations: CCCP, carbonyl cyanide m-chlorophenylhydrazone; TCS, tetrachlorosalicylanilide; TPP, tetraphenylphosphonium ion; AIB, $\alpha$-aminoisobutyrate.
} 
has been specified (Midgley, $1983 \mathrm{~b}$ ); K/HEPPS/glucose had the same composition except that $\mathrm{Na}^{\bullet}$ was replaced by $\mathrm{K}^{+}$. A third version of this buffer was designated Tris/HEPPS/glucose and had the following composition: $128 \mathrm{~mm}$-Tris base; $132 \mathrm{mM}$-HEPPS; $50 \mathrm{~mm}$-glucose. The composition of the buffer designated PBSG has been described (Midgley, 1983a).

Measurement of $A J B$ uptake. This was measured using a rapid filtration technique as previously described for $\Delta \psi$ measurements with this organism (Midgley, 1983b). The basic incubation system has been described (Midgley. 1983b). To vary the cation present, the organisms were harvested in Tris/HEPPS/glucose and diluted $\sim 20$ fold into the appropriate buffer.

Cells were preincubated for between 1 to $5 \mathrm{~min}$ prior to initiating transport by the addition of AIB. In experiments using jonophores or inhibitors, these were included in the preincubation period and were added as previously described (Midgley, 1983a). Initial rates were computed from duplicate incubations sampled over time intervals for which uptake was linear, generally during the first 20 min of uptake. Uptake was corrected for extracellular and filter binding using a control incubated on ice.

Respiration studies. These were carried out as previously described using the appropriate buffer system (Midgley, 1983a).

Extraction and identification of the intracellular product of $A I B$ accumulation. This was based on the previously described method (Midgley, 1978) in which cetls that had accumulated [ ${ }^{4} \mathrm{C}$ ]AIB were treated, after washing on a filter, with ice-cold $60 \%(\mathrm{v} / \mathrm{v})$ ethanol. This procedure released $>96 \%$ of the radioactivity present within the cells. The extract was concentrated by rotary evaporation and applied to the chromatographic and electrophoretic systems previously described (Midgley, 1978). Standards and radioactivity were detected as previously described (Midgley, 1978).

Protein determination. The method of Lowry was employed using cells digested in $1 \mathrm{M}-\mathrm{NaOH}$ for $10 \mathrm{~min}$ at $100^{\circ} \mathrm{C}$.

Chemicals. These were obtained from sources previously specified (Midgley, 1983a). Radiochemicals were obtained from Amersham.

\section{RESULTS}

\section{General characteristics of $A I B$ transport}

Preliminary experiments using the $\mathrm{Na}$ /HEPPS/glucose system, established that when washed cell suspensions of $T . b$. brucei $8 / 18$ were incubated at 25 or $37^{\circ} \mathrm{C}$ in a simple buffered system of adequate osmolarity, glucose-dependent uptake of $\left[{ }^{14} \mathrm{C}\right] \mathrm{AIB}$ could be observed (Figs 1 and 3 ). As shown, uptake at $25^{\circ} \mathrm{C}$ was linear for the time period studied whereas at $37^{\circ} \mathrm{C}$ the amount accumulated reached an apparent plateau and subsequently declined. This phase of decline occurred to a varying extent with different batches of the organism and probably reflected the acknowledged lability of the bloodstream forms at $37^{\circ} \mathrm{C}$ once removed from the host, rather than a characteristic of the transport system. Glucose-dependent respiration, which was used as an index of cell stability, decreased rapidly at $37^{\circ} \mathrm{C}$. The respiration of two batches of organisms [respiring initially at 160 and $130 \mu \mathrm{mol} \mathrm{O}_{2} \mathrm{~min}^{-1}$ (g protein) ${ }^{-1}$ respectively] declined to $50 \%$ of the initial values in $60 \mathrm{~min}$ and $35 \mathrm{~min}$. Greater stability was observed at $25^{\circ} \mathrm{C}$. However, since observations at $37^{\circ} \mathrm{C}$ were considered more relevant to bloodstream forms, the majority of experiments were conducted at this temperature.

Disruption of the cellular permeability barrier by the inclusion of nystatin $\left(10 \mu \mathrm{g} \mathrm{ml}^{-1}\right)$ or Triton X-100 $(10 \mu \mathrm{g} \mathrm{ml}-1)$ in the incubation medium abolished AIB uptake. The intracellular material accumulated after incubation with AIB under conditions as specified in Fig. I was isolated as described in Methods. This material had the same mobility as authentic AIB when tested in the systems described in Methods. Thus AIB was not metabolized significantly by the organisms under the conditions employed. Using a value for the cell water content of $\sim 2 \mathrm{ml}$ ( $\mathrm{g}$ protein) ${ }^{-1}$ derived from published data (Voorheis, 1971), the peak accumulation value observed at $37^{\circ} \mathrm{C}$ in Fig. 1 corresponded to an intracellular concentration of $10.3 \mathrm{~mm}$ and an accumulation ratio of $\sim 100$. The specific uptake rate was independent of protein concentration over the range 0.2 to $2 \mathrm{mg}$ protein $\mathrm{ml}^{-1}$.

\section{Kinetic studies of AIB transport}

Studies on the initial rate of AIB transport demonstrated the contribution of at least two components (Fig. 2). The apparent $K_{\mathrm{m}}$ for the saturable component was $4.6 \mathrm{mM} \pm 1 \cdot 1 \mathrm{mM}(n=$ 


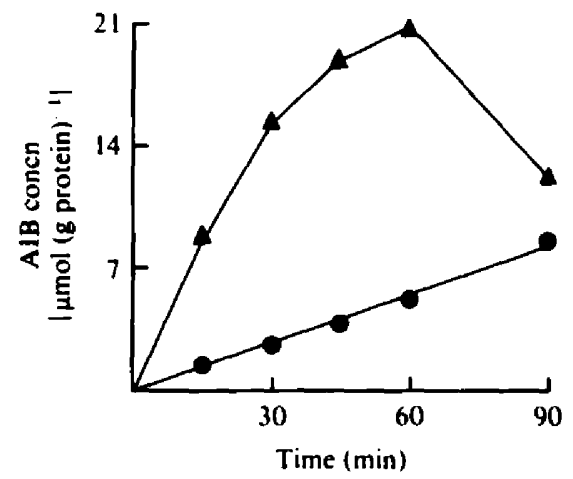

Fig. 1

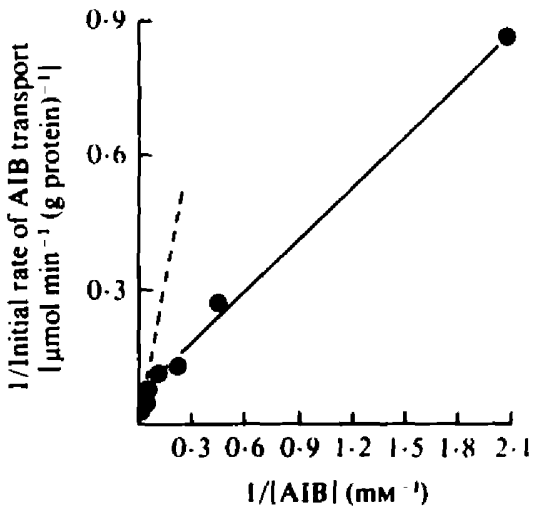

Fig. 2

Fig. 1. The uptake of $\alpha$-aminoisobutyrate by $T$. b. brucei $8 / 18$. Transport was measured in duplicate in the $\mathrm{Na} / \mathrm{HEPPS} / \mathrm{glucose}$ system using an AIB concentration of $100 \mu \mathrm{M}\left(4 \mu \mathrm{Ci} \mu \mathrm{mol}^{-1}\right)$ and a cell density of $0.36 \mathrm{mg}_{\mathrm{g}}$ protein $\mathrm{ml}^{-1}: A, 37^{\circ} \mathrm{C}: 0.25^{\circ} \mathrm{C}$.

Fig. 2. Double reciprocal plot for AIB transport by $T$. b. brucei 8/18. The initial rate of AIB transport was measured over a concentration range of $0.5 \mathrm{mM}$ to $40 \mathrm{mM}$ in the $\mathrm{Na} / \mathrm{HEPPS} / \mathrm{glucose}$ system as described in Methods.

5) while the apparent $V_{\max }( \pm S D)$ observed for this system with different batches of the organisms was $8.6 \pm 3 \mu \mathrm{mol} \min ^{-1}$ (g protein) ${ }^{-1}(n=5)$. The behaviour of the system detected at high AIB ( $>15 \mathrm{mM}$ ) was compatible with either entry by simple diffusion or the operation of a mediated system with a high $K_{\mathrm{m}}$ relative to the concentration range employed, since the Lineweaver-Burk plot for this range extrapolated through the origin. Thus for this system AIB transport was directly proportional to AIB with a proportionality constant ( \pm SD) of $0.46 \pm$ $0.23 \mu \mathrm{mol} \mathrm{min}^{-1}$ (g protein) $)^{-1} \mathrm{mM}^{-1}(n=5)$.

The specificity of the system operating at low AIB concentration was investigated in competition experiments with other amino acids using an AIB concentration of $0.5 \mathrm{~mm}$ (Table 1). At this concentration the flux via the saturable system constituted 60 to $84 \%$ of the total flux measured. The results were consistent with the saturable component being one of the neutral amino acid transport systems described by Voorheis (1971). The demonstration that valine acted as a competitive inhibitor with an apparent $K_{1}$ of $1.5 \mathrm{~mm}$ (data not shown) was consistent with this interpretation.

\section{Energy requirement for $A I B$ transport}

Bloodstream forms of $T . b$. brucei are dependent upon a supply of external substrate, such as glucose, for viability (Lumsden et al., 1973) and this was included in all buffers used in harvesting since otherwise, suspensions showing little metabolic activity were produced. The role of energy generation in the uptake of AIB was assessed by preparing cell suspensions in the usual manner and immediately before use preparing a further suspension in the absence of glucose, compensating for the osmolarity of the medium by use of an increased buffer concentration. AIB transport was glucose-dependent (Fig. 3). Also shown is the inhibitory effect of 2-deoxyglucose. The initial rate of AIB transport was inhibited 50 to $70 \%$ by $1 \mathrm{mm-salicyl-}$ hydroxamate, a concentration that abolished respiration and diverted glucose metabolism to an alternative mode generating less ATP (e.g. Voorheis, 1980). If inhibitory conditions that were too severe were employed, e.g. a combination of salicylhydroxamate plus glycerol (Brohn \& Clarkson, 1978) or 2-deoxyglucose in the absence of glucose, then the organism lysed rapidly. In the experiments presented here, lysis was assessed by measuring the turbidity of the cell suspensions and did not account for the observed inhibition of AIB transport, since lysis occurred only to the extent of 10 to $20 \%$ in a 30 min incubation period in the absence of glucose. 
Table 1. Specificity of a-aminoisobutyrate transport by $T$. b. brucei $8 / 18$

Transport was measured in the Na/HEPPS/glucose system. Presumed competitors were added 10 to I5 s prior to AIB (0.5 mM, $1 \mu \mathrm{Ci} \mu \mathrm{mol})$. Initial rates were calculated from four samples removed in the 10 min period after AIB addition. The values presented are the means of duplicate experiments with two independent batches of the organism. All the amino acids were of the $\mathrm{L}$ configuration. The absolute values of the control rates were 0.44 and $0.65 \mu \mathrm{mol} \mathrm{min}^{-1}$ ( $\mathrm{mg}_{\mathrm{g}}$ protein) ${ }^{-1}$.

$\begin{array}{lrc}\text { Amino acid } & \begin{array}{c}\text { Concn } \\ (\mathbf{m M})\end{array} & \begin{array}{c}\text { Relative rate of AIB } \\ \text { transport }\end{array} \\ \text { None } & - & 100 \\ \text { Serine } & 5 & 42 \\ \text { Threonine } & 25 & 16 \\ & 5 & 44 \\ \text { Valine } & 25 & 17 \\ & 5 & 31 \\ \text { Lysine } & 25 & 13 \\ & 5 & 103 \\ \text { Glutamate } & 25 & 82 \\ & 5 & 69 \\ \text { Phenylalanine } & 25 & 30 \\ & 5 & 30 \\ \text { Alanine } & 25 & 27 \\ & 5 & 32 \\ & 25 & 12\end{array}$

\section{Mechanistic studies of AIB transport}

The mechanism of energy-coupling to AIB transport was investigated by examining the effects of changing the composition of the medium used in the transport assays. Thus the buffer system used contained as cation either $\mathrm{Na}^{+}, \mathrm{K}^{+}$or trishydroxymethylammonium (Tris ${ }^{+}$). The organism was harvested and resuspended in Tris/HEPPS/glucose and then diluted so that the major cation was $\mathrm{Na}^{+}, \mathrm{K}^{+}$or Tris ${ }^{+}$. In a series of experiments the $\mathrm{Na}^{+}$- and $\mathrm{K}^{+}$-systems showed equivalent rates of AIB uptake, while the Tris ${ }^{+}$-system showed rates that were somewhat lower (Table 2). When initial rates of AIB transport were compared in the $\mathrm{Na} / \mathrm{HEPPS}$ system and the PBSG system, a traditional medium for handling trypanosomes (Lumsden et al., 1973), the rates obtained in the PBSG system were 60 to $76 \%$ of the rates in the $\mathrm{Na}$ /HEPPS system. Thus no stringent cation requirement for $\mathrm{AlB}$ transport emerged from these studies.

A second approach was to use the ionophores gramicidin and valinomycin and the protonophores CCCP and TCS to eliminate specific electrochemical gradients of ions across the cytoplasmic membrane of the organism (Fig. 4). The uptake of AIB, measured at $105 \mu \mathrm{M}-\mathrm{AIB}$, was severely inhibited by $30 \mu \mathrm{M}-\mathrm{CCCP}$ or $5 \mu \mathrm{M}-\mathrm{TCS}$, independently of whether the cation present was $\mathrm{K}^{+}$or Tris ${ }^{+}$(Fig. $4 c, d$ ) or $\mathrm{Na}^{+}$(data not shown). When $\mathrm{K}^{+}$was the cation present AIB transport was severely inhibited by the addition of $1 \mu \mathrm{g}$ gramicidin $\mathrm{ml}^{-1}$ or $1 \mu \mathrm{g}$ valinomycin ml-1 (Fig. 4a); when $\mathrm{Na}^{+}$was the cation present transport of AIB was inhibited by gramicidin but insensitive to valinomycin (Fig. $4 b$ ). Such behaviour would be expected for a transport system driven by the $\Delta \psi$. When the sensitivity of the initial rate of AIB transport to gramicidin or valinomycin was tested in the Tris/HEPPS system the following rates, expressed

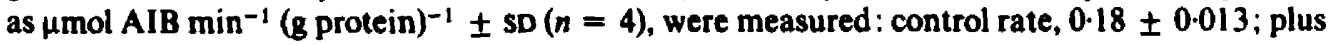
$1 \mu \mathrm{g}$ valinomycin $\mathrm{ml}^{-1}, 0.17 \pm 0.03$; plus $1 \mu \mathrm{g}$ gramicidin $\mathrm{ml}^{-1}, 0.14 \pm 0.023$. In these experiments the organism was incubated with valinomycin or gramicidin for $5 \mathrm{~min}$ prior to AIB addition. Increasing the preincubation time to $10 \mathrm{~min}$ resulted in no increase in inhibition. Thus under conditions where the addition of ionophores allowed either $\mathrm{Na}^{+}$or $\mathrm{K}^{+}$to reach passive flux equilibrium (i.e. $\Delta \bar{\mu}_{\mathrm{K}}$, or $\Delta \mu_{\mathrm{Na}^{+}}=0$ ), but where extensive membrane depolarization was limited by the low concentrations of $\mathrm{Na}^{+}$or $\mathrm{K}^{+}$present, then AIB transport was largely unaffected.

The initial rate of uptake of AIB measured using $52.5 \mu \mathrm{M}-\mathrm{AlB}$ was shown to be inhibited by 


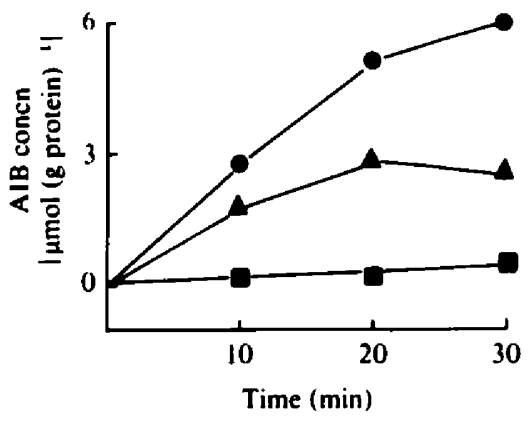

Fig. 3

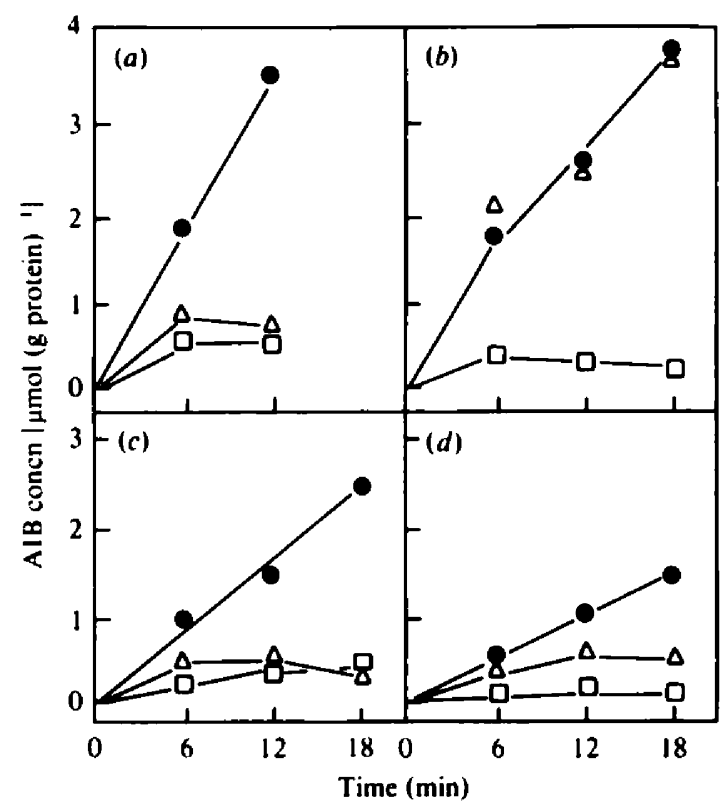

Fig. 4

Fig. 3. Energy dependence of $\alpha$-aminoisobutyrate uptake by $T$. b. brucei $8 / 18$. Transport was measured at $37^{\circ} \mathrm{C}$ in the $\mathrm{Na} / \mathrm{HEPPS} / g$ lucose system (O), the $\mathrm{Na} / \mathrm{HEPPS} / \mathrm{glucose}$ system plus 2-deoxyglucose $(\boldsymbol{A})$ (the concentrations of glucose and 2-deoxyglucose were 20 and $30 \mathrm{mM}$ respectively) and in $\mathrm{Na} / \mathrm{HEPPS}$ alone (D).

Fig. 4. Effect of ionophores on the transport of AIB by $T$. b. brucei 8/18. AIB transport, measured at $105 \mu \mathrm{M}$-AIB, was performed as described in Methods. The results presented were obtained with independent batches of cells. (a) K/HEPPS/glucose: $O$, control; $\Delta$, plus $1 \mu \mathrm{g}$ valinomycin $\mathrm{ml}^{-1} ; \square$. plus $1 \mu \mathrm{g}$ gramicidin $\mathrm{ml}^{-1}$. (b) $\mathrm{Na} / \mathrm{HEPPS} / \mathrm{glucose}:$. control $; \triangle$. plus $1 \mu \mathrm{g}$ valinomycin $\mathrm{ml}^{-1} ; \square$, plus $1 \mu_{\mathrm{B}}$ gramicidin ml-1. (c) K/HEPPS/glucose: 0 , control; $\triangle$, plus $30 \mu \mathrm{M}-\mathrm{CCCP}$; $\square$, plus $5 \mu \mathrm{M}-\mathrm{TCS}$. (d) Tris/HEPPS/glucose: control; $\triangle$, plus $30 \mu \mathrm{M}-\mathrm{CCCP}$; $\square$, plus $5 \mu \mathrm{M}-\mathrm{TCS}$.

Table 2. Effect of cations on the transport of AIB by T. b. brucei $8 / 18$

Initial rates of AIB transport were measured using $105 \mu \mathrm{M}$-AIB as specified in Methods. The values quoted are \pm SD.

Rate of AIB transport

Buffer system

Na/HEPPS/glucose
K/HEPPS/glucose
Tris/HEPPS/glucose
[ $\mu \mathrm{mol}(\mathrm{min})^{-1}$ (B protein) ${ }^{-1}$ ]

$$
\begin{aligned}
& 0.22 \pm 0.07(n=5) \\
& 0.21 \pm 0.08(n=4) \\
& 0.13 \pm 0.06(n=4)
\end{aligned}
$$

tetraphenylphosphonium chloride; when measured in the Na/HEPPS system $50 \mu \mathrm{M}$-TPP produced 35 or $54 \%$ inhibition with two independent batches of the organism. Previous experiments have shown that the maintenance of a $\Delta \psi$ in this organism is sensitive to similar concentrations of TPP (Midgley, 1983b).

\section{Interaction of inhibitors of $A I B$ transport with respiration}

In bloodstream forms of $T$. b. brucei, aerobic glycolysis produces pyruvate quantitatively as an end product and NADH is oxidized by a salicylhydroxamate-sensitive $\alpha$-glycerophosphate oxidase system (e.g. see Gutteridge \& Coombs, 1977). ATP is produced only by substrate level 
Table 3. Interaction of transport inhibitors with respiration in T. b. brucei 8/18

Rates of respiration were measured as previously described (Midgley, 1983a) using an $\mathrm{O}_{2}$-electrode. The values quoted are the means of two or three observations made with independent batches of the organism. The rates quoted in the presence of inhibitor were measured over the 2 min period immediately after the addition of inhibitor. The symbol ${ }^{\bullet}$ indicates that there was a time-dependent increase in inhibition following this period. The absolute value of the control rate $( \pm \mathrm{SD})$, corresponding to $100 \%$ was compiled from results with four independent batches of cells, and was $132 \pm 52 \mu \mathrm{mol} \mathrm{O}_{2} \mathrm{~min}^{-1}(\mathrm{~g}$ protein) $)^{-1}$.

\begin{tabular}{|c|c|c|c|c|}
\hline \multirow[b]{2}{*}{ Inhibitor } & \multirow[b]{2}{*}{ Conen } & \multicolumn{3}{|c|}{ Relative rate of respiration in: } \\
\hline & & $\mathrm{Na} / \mathrm{HEPPS} / \mathrm{glucose}$ & K/HEPPS/glucose & Tris/HEPPS/glucose \\
\hline $\begin{array}{l}\text { CCCP } \\
\text { TCS } \\
\text { Valinomycin } \\
\text { Gramicidin } \\
\text { Tetraphenylphosphonium } \\
\text { chloride }\end{array}$ & $\begin{array}{l}30 \mu \mathrm{M} \\
5 \mu \mathrm{M} \\
1 \mu \mathrm{g} \mathrm{ml}-1 \\
1 \mu \mathrm{g} \mathrm{ml}-1 \\
20 \mu \mathrm{M} \\
50 \mu \mathrm{M} \\
100 \mu \mathrm{M}\end{array}$ & $\begin{array}{c}83^{*} \\
62^{*} \\
100 \\
97 \\
92^{*} \\
80^{*} \\
70^{\circ}\end{array}$ & $\begin{array}{r}100 \\
64 \\
92 \\
100 \\
\text { ND } \\
\text { ND } \\
\text { ND }\end{array}$ & $\begin{array}{l}57 \\
67^{*} \\
93^{\circ} \\
100^{*} \\
\text { ND } \\
\text { ND } \\
\text { ND }\end{array}$ \\
\hline
\end{tabular}

ND, Not done.

phosphorylation and thus measurement of respiration provides a direct means of assessin glycolysis and hence ATP generation. The effect on $\mathrm{O}_{2}$ consumption of the ionophores anc protonophores used in this study was investigated in media of different ionic composition ( $\mathrm{Na}^{+}$ $\mathrm{K}^{+}$or $\mathrm{Tris}^{+}$) (Table 3). In some cases the values quoted may underestimate the degree o inhibition observed under the conditions of the transport assays since some of the inhibitors hac time dependent effects depending on the buffer system. It was noteworthy that CCCP in thi $\mathrm{K} / \mathrm{HEPPS}$ system, and valinomycin or gramicidin in either the K/HEPPS or Na/HEPPS systen brought about either no or very little inhibition of respiration yet these combinations depolarizt the cytoplasmic membrane (Midgley, 1983a,b) and inhibit AIB transport.

\section{DISCUSSION}

Our observations concerning the characteristics of AIB uptake by bloodstream forms of $T . b$ brucei $8 / 18$ suggest that AIB is a suitable probe to study the mechanism of energy-coupling tc active transport of amino acids in this organism. Kinetic studies indicate that AIB enters by twc processes. The transport component apparent at high concentrations of AIB was probably a second mediated system, despite the lack of saturation observed in the concentration range used. This was indicated by $>90 \%$ inhibition of AIB transport (measured at $40 \mathrm{~mm}$-AIB) by TCS, CCCP or 2-deoxyglucose (K. P. Coolbear \& M. Midgley, unpublished observations).

By using AIB, any complications arising from the subsequent metabolism of the transported compound are avoided and this factor may explain the discrepancy between previous results obtained using threonine (Voorheis 1980; Klein et al., 1980) and those presented here. Our observations support a scheme in which AIB enters via an $\mathrm{H}^{+}$-symporter, responding mainly to the transmembrane $\Delta \psi$ that has been demonstrated in this organism (Midgley, 1983a,b). Thus AIB transport was inhibited by the protonophores TCS and CCCP independently of the cation present, whereas valinomycin or gramicidin caused inhibition only in the presence of the appropriate cation. The lack of inhibition of AIB transport by gramicidin or valinomycin (in the absence of high external $\mathrm{K}^{+}$or $\mathrm{Na}^{+}$concentrations), which bring $\mathrm{Na}^{+}$and $\mathrm{K}^{+}$(gramicidin) or $\mathrm{K}^{+}$(valinomycin) into passive flux equilibrium, indicates that $\mathrm{AIB}$ uptake can operate when $\Delta \bar{\mu}_{\mathrm{K}}$, and/or $\Delta \bar{\mu}_{\mathrm{Na}}{ }^{*}=0$. In contrast, the sensitivity of AIB transport to protonophores was independent of the cation present and indicates that when $\Delta \bar{\mu}_{H^{*}}=0$, AIB uptake is inhibited. Thus $\Delta \boldsymbol{\mu}_{\mathrm{H}}$. plays a key role in driving AIB transport. Direct attempts to measure AIB-induced $\mathrm{H}^{+}$movements in non-metabolizing cells in the presence of a suitable counter-ion (e.g. $\mathrm{K}^{+}$plus valinomycin) have proved negative (M. Midgley, unpublished observations). We regard this as insufficient to disprove the model we propose. 
A major difficulty in interpreting such experiments is that the mechanism by which the membrane potential is maintained in these organisms is currently unknown. Eddy (1982) has discussed the importance of inhibiting proton recycling in order to demonstrate the true stoichiometry of a proton symport and has noted that it is not always feasible to make direct assays when a proton pump is not functioning. as the putative symport may not function sufficiently rapidly.

It could be argued that the crucial effects of inhibitors we have observed are in fact due to secondary or non-specific effects. Previous experiments (Midgley, 1983a,b) and data presented here have shown that the protonophores and ionophores $\left( \pm \mathrm{K}^{+}\right.$or $\left.\mathrm{Na}^{+}\right)$are without sufficient effect on glycolysis (a process that both requires and generates ATP) in this organism to explain the inhibition of AIB transport by these compounds. The simplest hypothesis is that the inhibitory effects on AIB transport are directly related to the inhibitory effects on $\Delta \psi$ maintenance. Since the external $\mathrm{pH}$ value was 8.0 in these experiments, it is probable that the $\Delta \psi$ was the major component of the $\Delta \boldsymbol{\mu}_{\mathrm{H}^{+}}$under the conditions studied. The magnitude of the observed $\Lambda \psi$ (Midgley, 1983 $\mathrm{b}$ ) is sufficient to account for the accumulation ratio of AIB reported here.

This work was supported by Grant no. $\$ 9150$ from the SERC. We thank Miss C. Page for enthusiastic technical assistance

\section{REFERENCES}

Brohn, F. H. \& Clarkson, A. B., JR, (1978). Quantitative effects of salycylhydroxamic acid and glycerol on Trypanosoma brucei glycolysis in ritro and in ivivo. Acta Tropica 35, 23-33.

EDdy, A. A. (1978). Proton-dependent solute transport in micro-organisms. Current Topics in Membranes and Transport 10. 279-360.

EDDY, A A. (1982). Mechanisms of solute transport in selected eukaryotic micro-organisms. Adrances in Microbial Physiology 23, 1-78.

Gutteridge, W. E. \& CoOmbs. G. H. (1977). Biochemistry of Parasitic Protozoa, p. 41. London: MacMillan Press.

HamiLton, W. A. (1975) Energy coupling in microbial transport. Adrances in Microbial Phy'siology 12. 153.

Klein, R. A., ANgus. J. M. Amadife, A. E. \& Smith, L. (1980). Stereospecificity of the threonine dehydrogenase from bloodstream forms of Tryponosoma brucei. Comparative Biochemical Physiology 66B. $143-146$

lumsden, W. H. R., Herbert. W. J. \& McNelllage, G. J. C. (1973). Techniques with Trypanosomes. Edinburgh \& London: Churchill Livingstone.

MidGLey. M. (1978). The transport of $\propto$-aminoisobutyrate into Crithidia fasciculata Biochemical Journal 174. 191202.
MIDGLEY, M. (1983a). The interaction of a fluorescent probe with Trypanosoma hrucei brucei: evidence for the existence of a membrane potential. FEMS Microbiology Letters 18, 203-206.

Midgley, M. $(1983 b)$. Further evidence for the existence of a membrane potential in Trypanosoma brucei brucei. Journal of General Microbiology 129. $2677-2679$.

Stephenson, M. C. \& Midgley, M. (1980). Measurement of the membrane potential component of the transmembrane proton electrochemical gradient in Crithidia fasciculata. Biochemical Society Transactions 8, 307308.

VoORheis, H. P. (1971). Amino acid Iransport in Trypanosoma brucei brucei. Transactions of the Royal Society of Tropical Medicine and Hygiene 65. 241- 242.

Voorheis, H. P. (1977). Changes in the kinetic behaviour of threonine transport into Trypanosoma brucei elicited by variation in hydrogen ion concentration. Biochemical Journal 164, 15. 25.

VoORheis, H. P. (1980). Energized amino acid transport by Trypanosoma brucei requires a glycolytic intermediate. Biochemical Society Transactions 8. 273-275 